\title{
Two Unique Golden Helmets
}

\author{
SEPARATE FINDS FROM PRE-ROMAN CELTIC FRANCE
}

\section{Christiane Eluère}

Museé des Antiquités Nationales, Saint-Germain-en-Laye, France

In 1981, a magnificent helmet was discovered buried inside a cave in Agris (Charente, Central-Western France) - probably from the rich sepulchre which is presently being researched in that area. The helmet is made of iron, and is covered with a bronze sheet, decorated with repoussé patterns, which is coated with a thin sheet of gold foil. Another precious material used in its decoration is coral (which is now white in colour), fixed to the helmet with gold-capped iron rivets, in patterns representing palmets and anthropomorphic faces. The neck-cover also seems to have been fixed in place by rivets.

Some parts of the helmet are missing: the top, which was probably decorated with coral buttons, and the cheek-covers (paragnatides), the imprints of which are still visible.

The helmet is now housed in the museum of Angoulême (Charente) and is soon to be testored; its study, as well as the continuing excavation of the Agris cave, will probably yield a wealth of information regarding this important find made by the French archaeologist J. Gomez. (In mid-1983 other gold fragments decorated with coral were also found in the cave.)

This is the second such Celtic golden helmet ever to have been found. More than 100 years ago, a similar helmet was discovered in a dried bank of the river Seine in Amfreville-sous-Les-Monts (Eure, Normandy), about $80 \mathrm{~km}$ west of Paris. The first helmet was, however, found without any other associated objects. It was offered to the Emperor Napoléon III and was exhibited for several years in the Louvre museum in Paris. It is now exhibited in the Musée des Antiquités Nationales at Saint-Germain-en-Laye, after having been restored during 1981 and 1982 by the Römisch Germanisches Zentralmuseum in Mainz, Germany. During restoration, some technical aspects of its manufacture were noted. It is somewhat taller than the Agris helmet, and the interior form was made very roughly of bronze showing evidence that previous repairs and adjustments had been carried out. The neck-cover, which was manufactured separately, was fixed in place by small bronze rivets. Over this part was fixed a decorative iron network in which flat glass beads were inserted. Above this has been fixed a band of gold sheet-decorated with tepoussé patterns typical of the triskele. Both bands were fixed in place by numerous rivets, the sharp points of which can still be felt in the inside of the helmet!

The Amfreville helmet (facing page) illustrates that the Celts favoured colour and extravagant decoration on most of their equipment. However, despite its rich appearance, the helmet was not the product of a highly skilled goldsmith. One wonders if the goldsmith tried to imitate a simpler model from, perhaps, Italy or somewhere in Central Europe. Indeed, the most recent hypotheses indicate that it was an imitation work in which the goldsmith had tried to utilise different metals and materials in order to create something sumptuous with a strong contrast of red and gold.

In any event these two helmets ate unique: their style and design would appear to date them between the third and fourth centuries B.C., the Agris helmet probably being older than the Amfreville one because of its taller shape and the use of coral on it (which was replaced on Celtic jewellery by glass or enamel at a later date).

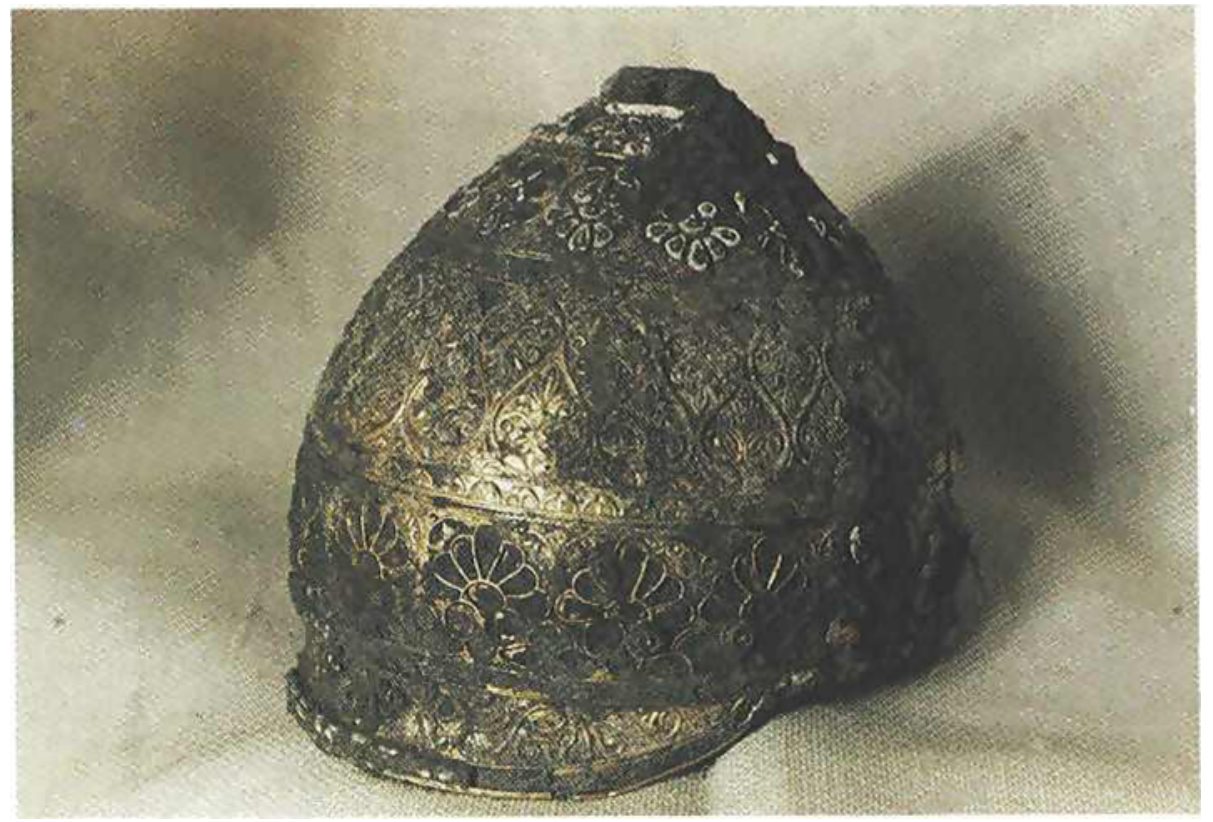

110
Helmet found at Agris (Charente) seen from the back, with the neck-cover. The height of the helmet is $21.4 \mathrm{~cm}$ and the lateral dimensions $23 \times 19 \mathrm{~cm}$. Photographed by J. Gomez - copyright teserved

Gold Bull., 1984, 17, (3) 
Why were these helmets manufactured at all? The Amfreville helmet is so small that it is difficult to imagine it being worn by anyone, except, perhaps, by a very young prince or warrior. One explanation could be that the helmets were used in one or other form of funeral ritual - others have been found in the past which were simple, yet functional, made only in bronze or iron, and which, buried in the earth, had been used as urns to contain the ashes of dead warriots.

Full view and detail for helmet found at Amfrevillesous-les-Monts (Eure). Height of helmet is $16 \mathrm{~cm}$. Held at Musée des Antiquités Nationales, Saint-Germanen-Laye, France

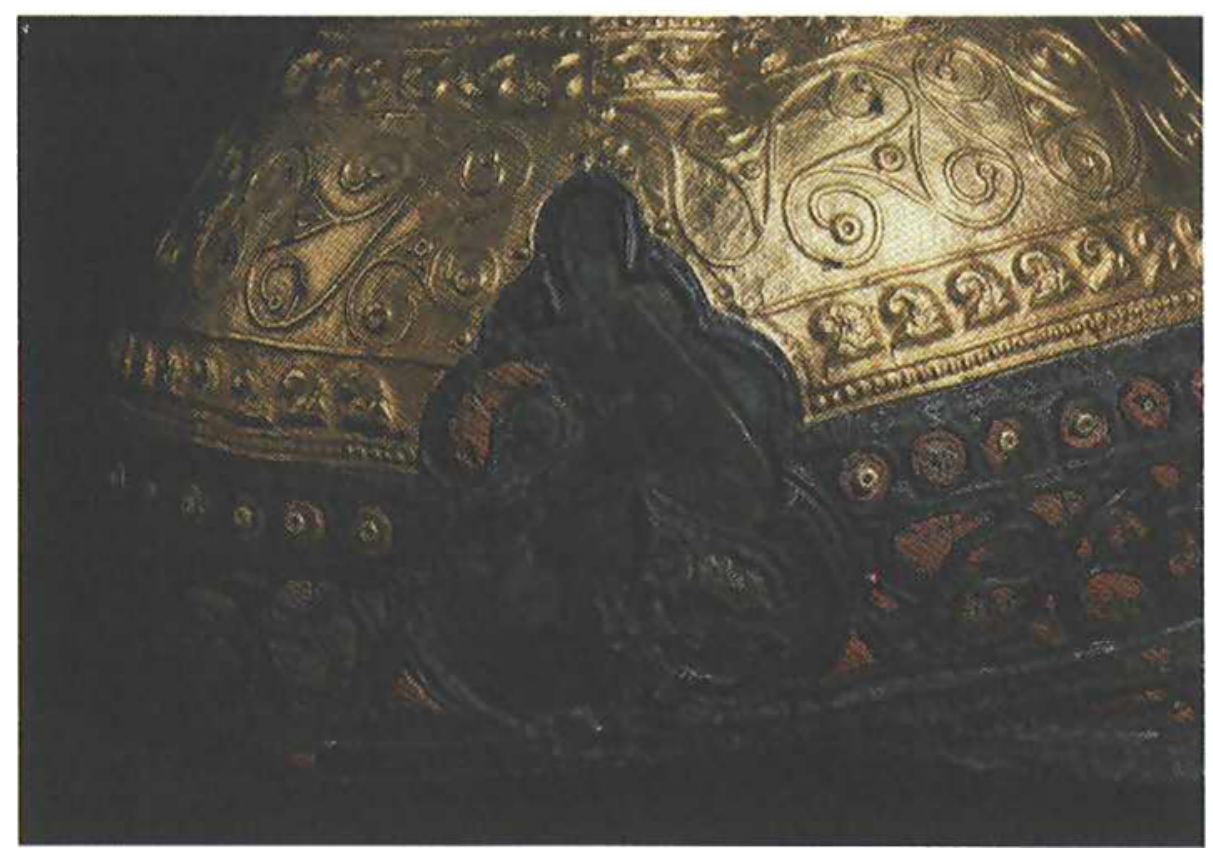

Gold Bull., 1984, 17, (3) 